\title{
An Assessment of the Social Science Research Environment of the Sri Lankan State University System
}

\author{
R. L. S. Fernando \\ University of Sri Jayewardenepura, Sri Lanka \\ D. W. K. Hemachandra \\ University of Sri Jayewardenepura, Sri Lanka
}

\section{A. Muthulingam}

University of Sri Jayewardenepura, Sri Lanka

\begin{abstract}
Higher education institutions play a vital role in society in varied capacities, and one major contribution amongst it all is conducting research as a part of knowledge creation and dissemination. Social Science Research thereby provides valuable input for policy makers, decision makers and the public, in order to encourage the well-being of the society. Previous studies have highlighted the importance of conducting social science researches to address social issues and improve quality of life. However, the number of research conducted in this discipline in Sri Lanka is not adequate when compared to that of other countries in the region. Hence, this study aims to explore the present status and challenges that hinder the number of social science research conducted by academics in State Universities in Sri Lanka. The study conducted a detailed literature review that was followed by indepth interviews with 50 academics representing five state universities in Sri Lanka. The universities were selected based on the availability of Social Sciences and Humanities Faculties/Departments. The data were then
\end{abstract}

\section{Corresponding Author:}

R. L. S. Fernando is a Senior Professor at the Department of Public Administration, Faculty of Management Studies and Commerce, University of Sri Jayewardenepura, Sri Lanka. E-mail: rlsf@sjp.ac.lk 
analysed qualitatively based on the Grounded Theory Method to achieve study objectives. The study revealed three main categories that limit the number of social science researches conducted in State Universities in Sri Lanka. They are; organizational factors, individual factors, and policy related factors. In addition, collaboration with other universities/ faculties, publication opportunities, research awards, and research allowance were identified as aspects in support of social science research in Sri Lanka. The study findings significantly help in policy making, to identify the present status as well as factors that can contribute to enhance the level of social science related research among academics of State Universities in Sri Lanka.

\section{Keywords}

Research Environment, Social Sciences Research, State Universities

\section{Introduction}

Higher education institutions play a significant role in society (World Economic Forum, 2017) by way of raising awareness, knowledge creation, skill development and value creation, which are essential elements in achieving a sustainable future (Cortese, 2003). Similarly, their contribution leads towards industrial innovation, and therefore economic development (Hatakenaka, 2015;Jayasundara, 2014), addressing an array of social issues such as, poverty, social disharmony, inequalities etc. (Hatakenaka, 2015; Social Science Research Council, 2016). Especially, in developing countries, the broader economic and social objectives are expected to be achieved through the higher education system (Altbach \& Salmi, 2011). However, many higher education institutions consider conducting research as challenging due to the lack of a research culture and relevant capacities (Hatakenaka, 2015). Higher education institutions in Sri Lanka similarly face many challenges when conducting research (University Grants Commission [UGC], 2014).

A country's research capacity can be measured in terms of the percentage of gross domestic product spent on research, number of researchers, number of publications in refereed journals and number of patents (The World Bank Group, 2018). Accordingly, Sri Lanka allocated 0.11 percent of its Gross Domestic Product (GDP) for research in 2013 
whereas the world average is 2.23 percent (The World Bank Group, 2018). Six research disciplines have been identified in Sri Lanka - natural science, engineering and technology, medical science, agricultural science, social sciences and humanities and other sectors. Allocation of funding for social sciences and humanities has been significantly reduced from 26 percent in 2004 to 7.3 percent in 2008 (Weerasinghe, 2013). According to Dhawan, Gupta, and Gupta (2015), Sri Lanka records the lowest publication growth rate when compared to Nepal, Bangladesh, India, and Pakistan. Pakistan's publication growth rate in social sciences is at 17.28 percent, which is nearly twice that of Sri Lanka, 9.76 percent.

The above indicates that there is a considerable gap in social sciences and other discipline related research in Sri Lanka, in comparison to other South Asian countries. Therefore, this study aims to achieve the following research objectives;

- to identify the present status of social science researches in State Universities of Sri Lanka

- to identify challenges faced by researchers in the field of social sciences in State Universities in Sri Lanka

- to determine the most significant factors in conducting social science researches in Sri Lanka

- to propose policy measures to create a favourable research environment for social science research, in State Universities in Sri Lanka

The findings of this research provide numerous input for policy makers as well as academic communities to take necessary actions to expedite research in social sciences in Sri Lanka. Furthermore, this is an initial study that assesses the social science research environment in Sri Lanka.

\section{Literature Review}

\section{Social Science Research}

Social Science is the science of people or collections of people, such as groups, firms, societies, or economies, and their individual or collective behaviours (Bhattacherjee, 2012). Research in social sciences focus on human behaviour, that is influenced by physical, social, temperamental, psychological and economic factors (Kumar, 2002). Social science researches provide substantial benefits to individuals and to local, regional, 
national, and international community's (Smith, 1998), since they study the behaviour of people and their decision-making process in society (Kumar, 2011). Thus, their findings help in understanding and bringing in necessary changes for a given issue or situation. Social scientists play an important role in the policy making process. For example, Singapore achieved economic development through a knowledge-based economy where research plays a vital role in economic development. Singapore invests approximately 2.2 percent of its GDP on research and development (The World Bank Group, 2018). However, the quality of social science research is questioned by researchers of the developed world in terms of trustworthiness of data, adequacy of information related to a focused issue, validity of the measurements and similar (Bulmer \& Warwick, 2001). Publications in social science research in South Asia have been doubled every six years during 1996-2013. For example, the average growth per year in social sciences in South Asia is 13.37 percent in comparison to the world average of 7.73 percent. India shares the largest portion of bulk publication in social sciences when compared to Pakistan, Bangladesh, Sri Lanka and Nepal (Dhawan et al., 2015).

\section{The Higher Education System and State Universities in Sri Lanka}

Education is a fundamental right in Sri Lanka, and thus the free education scheme has made a tremendous impact on social, economic and political developments in the country (Jayasundara, 2014). Sri Lanka has achieved the highest literacy rate in South Asia with a 92 percent, recording one of the highest literacy rates in the Asian region (Ministry of Higher Education www.mohe.gov.lk, 2018). In the past, higher education in Sri Lanka was provided through several prominent 'Pirivenas' (training centres for Buddhist monks). The origin of the modern university system in Sri Lanka dates back to 1921. The Ceylon University College was established affiliated to the University of London. According to Jayasundara (2014), the tertiary education system in Sri Lanka began formally in 1921, with the establishment of the colonial-oriented University College. The Ceylon University College functioned as an elite institution creating a crucial need to establish new universities that were responsive to the needs of common people (Karunanayake, 2009; Jayasundara, 2014). In 1956, the government decided to establish two new universities, by elevating the Vidyodaya and Vidyalankara Pirivens into universities. 
The present higher education framework in Sri Lanka is constituted by 15 state universities, 18 postgraduate and independent institutes, and hundreds of recognized higher educational institutes governed by the private sector (UGC, 2017). There are 57 private institutions currently operating in Sri Lanka offering foreign degrees (Hemmathagama, 2010). The Ministry of Higher Education (MOHE) oversees universities and higher technical institutes. The University Grants Commission on the other hand serves as the apex body within the state university system.

Out of 73 faculties in state universities, 23 are related to Social Sciences; this includes faculties in the field of Management (UGC, 2017). Major departments operated under the Social Science related Faculties are Economics, History, Geography, Sociology, Political Science, Archaeology and Philosophy. Since, the field of Management is concerned as one discipline of social sciences, the faculties relating to Management and Commerce of State Universities were also taken into consideration in this study.

As per the university statistics published by UGC (2017), there are 5669 permanent academic staff in State Universities and among them 2210 academics (39 percent) are attached to Social Sciences and Management Faculties. According to the UGC circular No. 711, the universities have been authorized to confirm probationary lecturers, who have a Masters' Degree of 02 years duration with a research component. Thus, it can be argued that the UGC, being the main administrative body of State Universities in Sri Lanka, has identified the importance of academic engagement in the field of researching.

The University of Colombo recently secured the $685^{\text {th }}$ rank in the Asian region in 2017 (www.mohe.gov.lk) and was placed in the $2238^{\text {th }}$ rank according to the excellence criterion of the Webometrics Ranking of Universities; which measures the number of academic papers published in high impact international journals. Consequently, the MOHE of Sri Lanka listed this University as the top-ranking university. In addition, University of Peradeniya has been quoted as the best in research by Research Gate in 2010 and gained the $1426^{\text {th }}$ rank under University Rankings for Academic 
Performance (Sirimane, 2014). Results of the renowned rankings such as, QS University Ranking and Times Higher Education Ranking provide evidence on how Sri Lankan Universities have not successfully retained significant positions in the Asian region for its quality and quantity of academic contribution (www.topuniversities.com). As per the website of Sri Lanka Journals Online (www.sljol.info), there are 81 journals catalogued on SLJOL listing 10,328 articles loading 1151 issues. Among them only 16 journals are related to social sciences including university journals. The numbers of journals published by State Universities account to a number of 19 out of which only 05 journals are directly related to social sciences. Apart from State Universities, other national level institutions such as Sri Lanka Institute of Policy Studies, National Centre for Advanced Studies in Humanities and Social Sciences, Central Bank of Sri Lanka, Social Scientists' Association, Sri Lanka Institute for Development Administration and other postgraduate institutes produce publications in the field of social sciences.

\section{Methodology}

The study conducted a detailed literature review and thereafter a primary and secondary data collection. Five State Universities were selected based on their availability of faculties of Social Sciences and Humanities. Accordingly, the University of Sri Jayewardenepura, University of Colombo, University of Kelaniya, University of Peradeniya, and the University of Ruhunawere selected as the sample for the study. In-depth and semi structured interviews were conducted with 50 academics based on the purposive sample strategy. Data collection was conducted during the period of January 2016 to March 2016. The sample represents junior and senior grades of faculty members of Social Sciences of the five selected universities. Convenient samples of journals published by the Faculties of Social Sciences of the selected universities were also collected as secondary data. The Grounded theory was chosen as the research method in order to achieve study objectives, due to its ability in building new theories based on qualitative data (Glaser \& Strauss, 2017). Thereafter a Content Analysis was utilized to analyse data in order to assess the present status of researches conducted in the field of social sciences within the State Universities system in Sri Lanka. 


\section{Results and Discussion}

\section{Present Status of Social Science Research}

To examine the present status of social science research conducted by academics in Sri Lanka's State Universities, five aspects were considered: scope of the journal, age of the journal, publication frequency, archiving policy, editorial policies, and number of research published in a volume- are the aspects which assess quality of research (Zehrer, 2007; Murphy, 1996). Please note that this study has not considered the number of research grants taken by the academics as well as the research publications in the ranked, indexed and referred international journals.

\section{Scope of the Journal}

This study considered 13 journals published in the fields of Social Sciences by the selected state universities. Therefore, it assesses the publication opportunities enabled within the considered universities. University of Sri Jayewardenepura publishes 08 journals in the areas of; Management, Business Economics, Accounting, Human Resource Management, Real Estate, Buddhist Studies and Multidisciplinary Studies. University of Kelaniya publishes six journals in relation to the fields of Management, Social Statistics, Human Resource Management, Humanities, Christian Culture, Hindi, and other Social Sciences. University of Colombo engages in the publication of three journals related to the fields of Law, International Law, and Business Management. University of Peradeniya involves in publishing one journal in the fields of Humanities and Social Sciences, while University of Ruhuna publishes two journals related to the fields of Social Sciences.

\section{Age of the Journal and Publication Frequency}

Most journals published by the University of Sri Jayewardenepura are annual publications, whilst two are published biannually. Four journals among them were initially published during the last decade whereas the other journals were published during the last two to three years. Although, certain journals incepted in 2004 and 2007, the continuity of their annual publication was interrupted. However, possibilities of continuing the publication of the aforesaid journals were observed in recent years. University of Kelaniya publishes five annual journals for not more than four 
years. However, one journal was initially published in 2006 and remained continuously published as a biannual journal. The tendencies of discontinuity after the inception of journals were noted as common scenarios.

University of Colombo publishes its two journals annually and semiannually. These journals have been successful in continuation over the past decades. Moreover, one of their journals were listed in the periodical indexes of Ulrich and Lex Opus. University of Peradeniya publishes the most long-standing academic journal in Sri Lanka, the University of Ceylon Review. This was discontinued in 1965 and started its publications again in two journals covering Humanities and Modern Studies. In 2002, two new journals have been introduced. University of Ruhuna commenced a biannual journal in 2004, which enables the publication of scholarly articles in the domains of Management and Finance. Further, the university publishes one e-journal that was initially released in 2013.

\section{Number of Research Papers Published in a Volume}

The journals of University of Sri Jayewardenepura, University of Peradeniya, and University of Colombo publish five research articles on a volume in average, while the University of Ruhuna, in average, publishes six articles in an issue.

\section{Editorial Policies}

The Peer Review method is a common and widely accepted approach used to select appropriate articles for publication by all universities considered in this study. The University of Sri Jayewardenepura, in specific, uses a double-blind peer review process to assess articles to be published in two journals.

\section{Archiving Policies}

The University of Sri Jayewardenepura and University of Kelaniya adopt the Open Journal Systems 2.4.0.0, which is an open source journal management and publishing software to ensure open access to knowledge. University of Peradeniya and University of Ruhuna publish in both printed and online versions. This is commended that trend enables accessibility to the widest possible readership. 


\section{Challenges faced by Social Science Researchers}

After identifying the present status of social science research in state universities in Sri Lanka, the study investigates challenges for conducting social science research in Sri Lanka. Fifty in-depth interviews were conducted to identify the perception on challenges faced by academics in conducting research. Figure 1 presents these challenges.

\section{Research Culture}

The Research Culture is an individual's capacity to undertake research activities. This capacity can be built, enhanced and refined through proper training (Lodhi, 2012). Majority of the sample highlighted that there is a growing attention to enrich the research culture within the Sri Lankan state university system. All universities conduct annual research conferences and symposiums in which hundreds of research papers are presented annually. However, when compared to developed countries, the number of research in the state university system in Sri Lanka is low.

According to respondents, one of the main reasons is present recruitment policies. For instance, probationary lecturers are recruited based on academic excellence of their bachelor's degree. As they are in their early career, they may not attain adequate research skills and experience. Therefore, it is suggested that the university may take research orientation of academic staff into consideration at their recruitment and selection (Lodhi, 2012).

\section{Academics' Involvement in Research}

The nexus between research and teaching among academics have been discussed throughout academic literature. Academics need to understand the importance of research as part of their teaching process in order to improve the quality of teaching. Through detailed research, students develop critical thinking expertise, as well as effective analytical, research, and communication skills that are globally sought-after and incredibly beneficial and ultimately, research is essential to economic and social development of our globalized society, forming the foundations governmental policies around the world (University of Skoyde, www.his.se, 2016). This is further confirmed that several interviewees in this study. According to them, some 
academics involve in research to secure promotions and their annual research allowance. This may hamper the quality of research. Two examples from academics of the University of Peradeniya and University of Ruhuna state that;

"In Sri Lanka, most of the research conducted by the academician is only for the purposes of applying for promotions. Very limited research is being conducted for solving the practical issues".

"It is very rare that the people do research for the real needs of the country. Due to this reason, the quality of those promotionoriented research is poor."

\section{Figure 1: Challenges for Conducting Social Science Research}

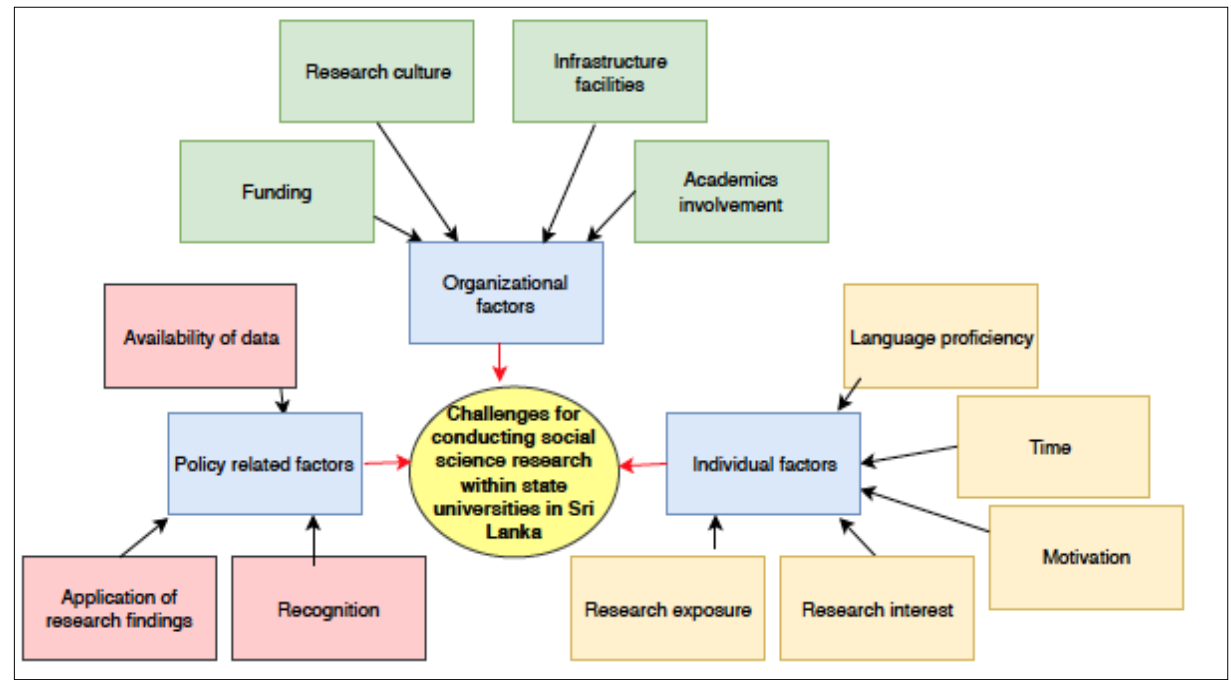

Source: Field data

\section{Time Constraint}

More than 40 respondents out of 50 express that 'time' is a constraint to conduct research. They argue that Social Sciences and Management Faculties comparatively produce a large number of graduates than other faculties. Hence, academics spend more time on lectures, marking scripts and assignments, administrative work and counselling work which limit their time for engaging in research. According to Bland and Ruffin (1992), 
research success was significantly affected by heavy teaching and/or administrative responsibilities. Winter and Sarros (2002) revealed that relieving researchers of large administrative workloads should lower the stress levels of staff and help in raising the department's research profile.

Some respondents pointed out that even though there is a considerable amount of research being conducted annually; most of them are based on archives/library research since they do not have time to carry out field research. Further, some junior academics noted that they prioritize other work which requires less time than undertaking research which is time consuming. However, a few respondents perceive that academics should have the capability of managing work and allocating time for research. University academics have job security; hence, doing research is not compulsory. This may make them reluctant in engaging in research and publications.

\section{Relatively low priority/recognition}

In comparison to natural sciences, social science research is given low priority. Some academics believe that the society is somewhat reluctant to accept the findings of social science research unlike that of natural sciences. In addition, some academics also felt that the government does not pay attention to the findings of these researches in solving societal problems; thus, discouraging academics in conducting research.

Few young academics further revealed of certain senior academics being reluctant in giving them opportunities to improve their research skills. They also noted that recognition was not given for their work despite them producing quality research. Hence, poor recognition to social science research affects the quality and the quantity of research since recognition for research is one major factor influencing the development of a research culture.

An academic employed at the University of Kelaniya (2016) expressed the following view.

"Anyone can get a research paper published on a journal by spending \$500. However, publishing it on an index journal does 
not attest to its quality. In that case, the extent to which a research can be applied in solving social problems and the value it adds to society should be considered when evaluating research quality."

An academic from the University of Ruhuna (2016) had these thoughts to share.

"There is no point of doing social sciences researches. The problem is no recognition or appreciation for them."

\section{Challenges in Data Collection}

As social science researches examine human behaviour, the data collection process proved challenging due to: poor infrastructure facilities, lack of interest of respondents, and the reliability of data. The study findings revealed that poor infrastructure facilities affect the quantity of social science research conducted in Sri Lanka. For example, proper transport modes for conducting field surveys.

"I am not satisfied about the facilities available in our faculty. We don't have necessary vehicle facilities for field visits, enough monetary facilities and etc. I know that certain countries with lowincome allocate more money on research" (An Academic, University of Peradeniya, 2016).

Lack of interest of respondents similarly affects the number of social science research. Due to various reasons, achieving a reasonable amount of completed questionnaires was a major challenge. Most respondents were not supportive of data collection, partly because they believed the study to be irrelevant to them or since they could not find time to do so.

The reliability of data was yet another challenge faced by social science researchers. A respondent (University of Colombo, 2016) explained that,

"When compared to other disciplines, the social sciences research involves getting data related to human behaviour and attitudes thus getting accurate data is a big challenge." 
Available secondary data in the government institutions is also not accurate or updated; thus, could mislead the findings of the research.

\section{Fund Constraints}

The state university system has a well-established mechanism that has been developed over time in order to grant research funds. A majority of academics accepted that their universities provide opportunities to apply research grants and believed that it was a great motivation in conducting researchers. Academics are however critical on the existing research grant process due to their rigid rules and regulations, insufficiency of grants, and the lack of awareness of grants.

According to respondents, rigid rules and regulations are a barrier for applying, utilizing and settling research grants. Several academics mentioned that the documentation with relation to research grants were time consuming. Similarly, most grants were not adequate to carry out quality research. Academics from the Faculty of Humanities and Social Sciences of University of Sri Jayewardenepura and the University of Kelaniya indicated that the insufficiency of research grants have restricted them from hiring research assistants.

"The university provides a limited amount of funds and when that money is divided among several academics, one can only access a very limited amount" (An Academic, University of Ruhuna, 2016).

However, one could argue that even though certain academics mentioned research grants as inadequate, it may not be accurate for certain universities located in the Western Province.

The lack of awareness on available funding sources is another limiting factor. Some argued that they could apply for funds only at the beginning of the year. However, there are fewer academics who find the existing funding process to be flexible and sufficient. Although resources are essential for research productivity, the existing in a unit is not sufficient: they must also be obviously accessible (Bland \&Ruffin, 1992). 


\section{Motivation}

Motivation of academics to do research is another issue. Most of academics engage on research only for their promotion. As per the existing promotion scheme of academics, they could claim marks for the number of research papers presented at conferences, number of articles published in journals, number international publications and publications in prestigious journals, etc.

"Most of the academics do research for their promotions and research allowance. Only a limited number of researches are related to the real needs of the country. Due to this reason, I think that the quality of those 'promotion-oriented researches' are poor" (An Academic, University of Ruhuna, 2016).

"with reference to the UGC Circular No. 916, marks allocation in the promotion scheme is problematic. Marks allocated for the research paper published in indexed journals and marks for Ph.D. research supervision have a significant difference. It is very difficult to publish in indexed journals and it takes sometimes three to four years for the review process. But one could collect more marks by supervising Ph.D. researches than a research paper published in an indexed journal within the same time period" (An Academic, University of Ruhuna, 2016).

\section{Research Interest}

Some respondents also argued that after receiving promotions, academics may refrain from conducting research. For instance,

"even after they became a professor, they may not engage in research. But in some countries, for example in Norway, academics have to continuously conduct research, if not their professorship will be cancelled" (An Academic, University of Ruhuna, 2016). 
Most respondents believe that the first and foremost aspect is the interest of conducting a research, since it would motivate the person to overcome barriers. Some argued that the reason to not be involved in research were attitudes; since despite facilities being made available, they are not interested in utilizing them.

"Another problem is the attitude of certain academics. One could climb the career ladder by performing extra duties in universities rather than doing research. Thus, what is the point of hard work and research, since a good salary, a better position and recognition can be achieved by doing administrative work." (An Academic, University of Ruhuna, 2016).

Motivation or interest of academics has a great impact on research work and its quality (Bland and Ruffin, 1992).

\section{Lack of Research Exposure}

Despite the research culture within the state university system, research in the field of social sciences is far behind from the main stream due to less research experience. This is primarily a result of the difficulties that academics in social sciences face in finding opportunities for pursuing their $\mathrm{PhD}$ in comparison to those of other fields.

A few young academics mentioned that the lack of research expertise limits their performance. For instance,

"Lack of experienced senior researchers to consult is a barrier to conduct researches." (An Academic, University of Kelaniya, 2016) and "Normally our academic staff are supportive, but we are lacking senior academics in our faculty" (An Academic, University of Peradeniya, 2016).

Apart from the above factors, some academics stated that the lesser number of international publications and lack of publication experience to be common in the field of social sciences. 


\section{Lack of Other Facilities}

Essential research resources are necessary to carry out a research programme (Bland \&Ruffin, 1992). Other facilities may include library facilities, financial support for publications, technical and other assistance. Some academics responded that even though those facilities have been gradually developed, most of the facilities are yet to be sufficiently equipped.

According to the respondents' views, the following issues related to library facilities affect the quality and quantity of social science research;

- limited opportunities for online access,

- less facilities to check plagiarism,

- limited access to latest text books,

- limited financial assistance for international publications,

- lack of technical and other facilities,

- lack of facilities for data analysis (advanced software packages, and limited access).

\section{Lack of Proficiency in English}

Many faculties of social sciences offer degree programmes in the medium of Sinhala while most publications are available in English. This has been highlighted as a major challenge among academics in Social Science. For instance,

"in Arts Faculties we teach in three languages, but many other Faculties use only English language, therefore, we have fewer opportunities to publish our papers" (An Academic, University of Peradeniya, 2016).

Other related problems could be listed as follows;

- due to less usage of English language in some Social Sciences Faculties, facilities provided by the universities are not being used,

- most books and journals are in the English language and it constraints the access to new knowledge,

- disusing ICT facilities, 
- reluctance to apply for research grants as it has to be submitted in English,

- inability to publish in international journals.

A respondent from the University of Sri Jayewardenepura (2016) mentioned that,

"one of the big issues that academics of Social Sciences face is the language. Most of their researches are in Sinhala, but publication opportunities are limited to researches in English."

\section{Poor Utilization of Research Findings}

Social science research dissertates social problems. Therefore, academics indicate that if a particular research does not address an existing social issue, it results in being worthless. Miller and Fredericks (2000) indicated that the social science research findings are largely irrelevant to the actual concern of policymaking.

"In Sri Lanka, most of the researchers carry out academic researches which are essential for promotions. Industrial researches that are practically applicable are therefore rare. Despite the number of researches completed by academics increase comparatively, their applicability remains questionable" (An Academic, University of Peradeniya, 2016).

Some academics are disappointed because there are many good researches which have real practical applications but no proper mechanism in utilizing their findings.

"It felt as though individuals were doing policy relevant work because of their own interests, they were putting the results in the public domain in academic journals, and it was up to policy makers and practitioners to make what use they could of it. This is a very passive approach to making a contribution to the wider policy arena" (Lewis, 2002 as cited by McNay, 2007). 


\section{The Conducive Factors that Aid in Conducting Social Science Research}

Based on interviews, several factors were identified as significant in their contribution towards enhancing the quality and quantity of social science research. Those are namely, research rewards, research allowance, collaboration among academics and awareness about international publications.

\section{Research rewards}

Most academics interviewed agreed that the existing award system highly motivated them in engaging in research. They highly appreciated the existing research award system. For instance,

"the existing award system and conferences organized are good to encourage academics in doing more research." (An Academic, University of Sri Jayewardenepura, 2016) and "Each year, the Vice Chancellor's award is being offered to the best researcher. I think it is a good motivational factor." (An Academic, University of Kelaniya, 2016).

Figure 2: Conducive Factors that Aid in Conducting Social Science Research

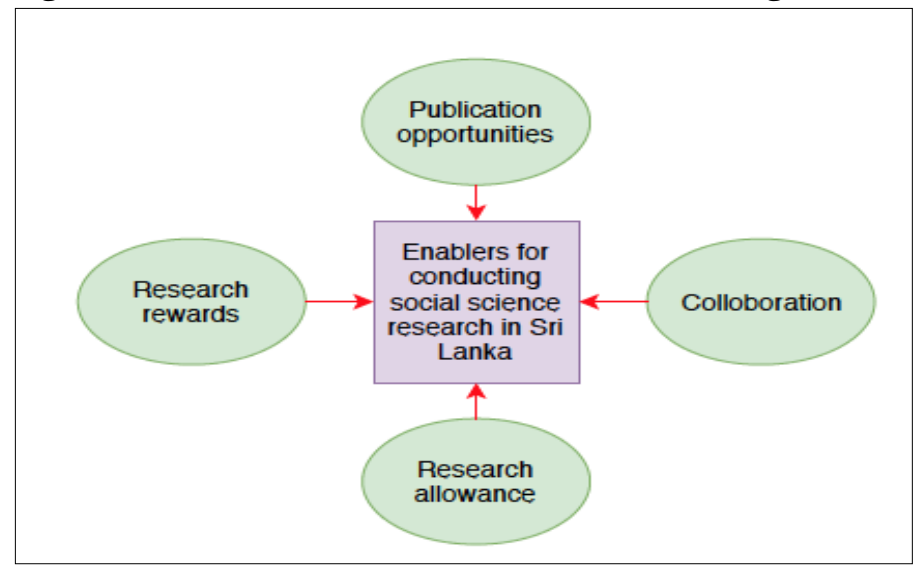

Source: Field data 


\section{Research allowance}

Bland and Ruffin (1992) suggested monetary bonuses as an influential factor to encourage the conducting of researches. For example,

"When applying for research allowance we may submit a research proposal. Therefore, without intention a research plan is developed in our mind. So, I believe that the allowance is a good motivational factor." (An Academic, University of Colombo, 2016).

Conversely, certain responses showcased apprehension on research allowance pointing that it forces academics to submit a mere report with no consideration towards its quality. Some argued that this may also be a factor towards the increase of research projects that contain questionable quality. For example;

"due to research allowance, the number of researches are increasing. However, no one evaluates the quality of those researches. This is the biggest problem in the field of Social Sciences" (An Academic, University of Peradeniya, 2016).

Fewer academics criticized the amount received and pointed it as being inadequate. Apart from all, a few of the respondents mentioned that research allowance is introduced not to do research, but as a solution of salary increment. For example,

"most of the academics are doing research for research allowance.

But, I think it is something given to us as a salary increment" (An Academic, University of Kelaniya, 2016).

\section{Collaboration among academics}

All respondents accepted that the collaboration among university academics would create a favourable atmosphere to carry out research. Meanwhile, some of them emphasized that a group research is better in quality than individual work. Thus, encouraging faculty collaboration may influence positively in the development of research cultures in universities. 
Highly productive faculty members maintain professionally meaningful relationships with colleagues (Bland \&Ruffin, 1992). For instance,

"There is a good collaboration among our colleagues. They are willing to help in research work of others" (An Academic, University of Kelaniya, 2016).

"There are informal academic discussions about research work. Senior academics support junior academics" (An Academic, University of Peradeniya, 2016).

Thus, research-oriented co-workers support in creating a collaborative environment. Meanwhile, one senior academic indicated that even academics work together within the faculty; it is very rarely they work with other faculties. For instance,

"Research related discussions are going on among academics. But those are related to their own disciplines with no interdisciplinary or multidisciplinary discussions or research works." (An Academic, University of Peradeniya, 2016).

This highlights the lack of multidisciplinary collaboration. Further, though academics are willing to support research efforts of others, they are unable to do so due to time constraints. For example,

"Colleagues are willing to support for researches. But we do not have time." (An Academic, University of Ruhuna, 2016).

Some respondents critiqued academic collaboration mentioning that despite it enhancing academic and research performance, it is not up to standard among staff due to several reasons in which academic jealousy stands apart as a prominent issue affecting the entire university system. For example,

"collaboration in our faculty is poor. I have worked with other faculties in multidisciplinary researches. I observed how their colleagues are working together. It is an attitude lacking among 
academics of Social Sciences" (An Academic, University of Ruhuna, 2016).

"Due to academic jealousy, colleague- support is not at a satisfactory level" (An Academic, University of Kelaniya, 2016).

"No one is willing to help others, because of academic jealousy" (An Academic, University of Colombo, 2016).

\section{Factors related to Publications}

New knowledge can be disseminated through research publications. There are several conferences and journals published by universities and other higher education institutes in Sri Lanka. Apart from that, academics are assisted in presenting and publishing their research findings internationally. McNay (1997) found that when academics are encouraged to publish in prestige academic journals, their targeted output increases preceding efforts. However, academics have varied opinions about international publications. For example,

"Indexed journals in the Social Sciences field are not adequate. So we have to face many problems when we intend to publish our papers" (An Academic, University of Sri Jayewardenepura, 2016).

Respondents emphasized that the lack of knowledge; less international research exposure, the language barrier, high publication and refereed fee, unavailability of access to current and updated literature, the long reviewing cycle as other crucial factors that hamper international publication efforts.

\section{Conclusion}

When identifying the present situation of social science research within Sri Lankan State Universities, an attempt was taken to assess the quality and quantity of research outputs of five Social Sciences and Humanities Faculties for the past five years.

Scope of the journal, age of the journal and publication frequency, number of research published in a volume, editorial policies and archiving 
policies (Zehrer, 2007; Murphy, 1996) were used to assess the present status of research in State Universities in Sri Lanka.

The study revealed that the latest journals related to the field of Social Sciences introduced by State Universities are new to the field and thus are challenged with a relatively long publication cycle (Chen \& Holsapple, 2013). Most journals published by State Universities during the last decades were subjected to publication discontinuity while the recently launched journals have not been so.

Most of these journals are not indexed or internationally recognized. Thus, these publications are not under the range of impact-based journal quality assessments. Chen \& Holsapple (2013) identified that relatively new journals, niche journals, journals in a formative discipline and non-English journals are subjected to this limitation.

The recruitment of academic staff to higher educational institutions in Sri Lanka can play a crucial role in setting the expected level of performance for each stage of an academics' career. Accordingly, the Scheme of Recruitment of academic staff mentioned on UGC Circular No. 165 of depicts the qualifications for promotions. It indicates that, active engagement in research is only an optional criterion rather than a mandatory performance norm that persuades promotions.

Further, to be promoted as Associate Professor on merit, a Senior Lecturer has to provide evidence of researches after his her appointment as a Senior Lecturer. However, for the normal promotion, a Senior Lecturer who has served for at least two years on the maximum of the salary scale or has served ten years in the grade Senior Lecturer can be considered for promotion if helshe has research publications or other acceptable evidence of research or is an outstanding teacher. This method of promotion also manifests the requirement of research publications as an optional qualification among other criteria for the promotion. Therefore, conducting researches is not an obligatory requirement for academics in state universities to secure promotions or sustain career development. 
The study assessed the present research environment pertaining to fields of social sciences and disclosed several issues and challenges including, time constraints, limitations in data collection, availability of funds, language proficiency, difficulties in publishing research, lack of other facilities such as library facilities and limited online access.

Research rewards, research allowances, collaboration among academics and factors related to publications are significant determinants that affect the conduct of social science research in State Universities in Sri Lanka. Therefore, allocating more time for research, enhancing recognition, maintaining a flexible process for obtaining funds, evaluating researchers' performance regularly, changing and motivating the attitudes of academics, increasing research exposure and other necessary facilities, improving language skills and encouraging the use of research findings for policy making and problems solving are the suggested recommendations to increase the quantity and quality of Social Science research in State Universities in Sri Lanka. Thus, this research calls for future studies to empirically validate the findings of this qualitative study. Further, this research can be extended by including the number of research grants received by academics and considering publications at ranked indexed referred international journals.

\section{References}

Altbach, P. G., \& Salmi, J. (2011). The road to academic excellence. Washington DC: World Bank.

Bhattacherjee, A. (2012). Social science research: Principles, methods, and practices. Florida: University of South Florida.

Bland, C., \& Ruffin, M. (1992). Characteristics of a productive research environment: Literature Review. Academic Medicine,67(6), 385-397.

Bulmer, M., \& Warwick, D. (2001). Social research in developing countries. London: Routeledge.

Chen, L., \& Holsapple, C. W. (2013). Evaluating journal quality: Beyond "expert" journal assessments in the IS discipline. Journal of Organizational Computing and Electronic Commerce, 23(4), 392-412. 
Cortese, A. D. (2003). The critical role of higher education in creating a sustainable futue. Planning for Higher Education, 31(3), 15-22.

Dhawan, S. M., Gupta, B. M., \& Gupt, R. (2015.) Social science research landscape in South Asia: A comparative assessment of research output published during 1996-2013. Library Philosophy and Practice (ejournal). Retrieved from http://digitalcommons.unl.edu/cgi/viewcontent.cgi?article=3355\&conte $\mathrm{xt}=$ libphilprac

Glaser, B. G., \& Strauses, A. L. (2017). The discovery of grounded theory: Strategies for Qualitative research.London: Aldine Publishing Company.

Hatakenaka, S. (2015). The role of higher education institutes in innovation and economic development. International Higher Education, 47,1-2.

Hemmathagama, A. (2010). Sri Lanka: Establishment of non-government universities. Asian Tribune: World Institute for Asian Studies, $12(1593$. Retrieved from http://www.asiantribune.com/news/2010/12/10/srilanka-establishment-non-government-universities.

Jayasundara, N. S. (2014). Higher education in Sri Lanka: Implementation in state universities. Scientific Research Journal, 2(2), 41-44.

Karunanayake, M. M. (2009). University of Sri Jayewardenepura: Towards meeting national aspirations. Vidyodaya Jounal of Humanities and Social Science, Joint Golden Jubilee Issue, 1-32.

Kumar, R. (2002). Research methodology in social science. India: Sarup and Sons Publishers.

Kumar, R. (2011). Research methodology (3rd ed.). India: Sarup and Sons Publishers.

Lodhi, A.S. (2012). A pilot study of researching the research culture in Pakistani public universities: The academics' perspective. Procedia Social and Behavioral Sciences, 31(1), 473 - 479.

McNay, I. (2007). Research assessment: Researcher autonomy. International Perspectives on Higher Education Research, 4(1), 183-216.

Miller, S. I., \& Fredericks, M. (2000). Social science research findings and educational policy dilemmas: Some additional distinction. Education Policy Analysis Archives, 8(3). 
Murphy, P. (1996). Determining measures of the quality and impact of journals, national board's commissioned report series. Canberra: Australian Government Publishing Service.

Sirimane, S. (2014). Make university life the best experience - VC peradeniya university. Retrieved from http:// archives.sundayobserver. lk/2001/pix/PrintPage.asp ?REF=/2014/04/06/fea12.asp

Smith, V. H. (1998). Measuring the benefits of social science research. Washington DC: International Food Policy Research Institute.

Social Science Research Council (2016). Science and contemporary social problems. Retrieved from https://items.ssrc.org/social-science-andcontemporary-social-problems/ stat_2017/Chapter\%205.pdf

The World Bank Group (2018). Indicators. Retrieved from http://data.worldbank.org/indicator?tab=all

The World Bank Group (2018). Research and development expenditure (\% of GDP.) Retrieved fromhttps://data.worldbank.org/indicator/GB.XPD.RSDV.GD.ZS

University Grants Commission (2014). DRIC progress report, Sri Lanka. Colombo: Author. Retrieved fromhttp://www.ugc.ac.lk/downloads/dric/DRIC_Progress_Report_201 4.pdf

University Grants Commission (2017). Sri Lanka university statistics, Sri Lanka. Colombo: Author. Retrieved from http://www.ugc.ac.lk/downloads/statistics/ stat_2017/Chapter\%205.pdf

Weerasinghe, M. C. (2013). R\&D country profile Sri Lanka, Presentation for the regional consultation for developing a strategic work plan as a follow-up of consultative expert working group on research and development: Financing and coordination, Bangkok, Thailand, 25-26 July 2013. Retrieved from http://www.searo.who.int/entity/intellectual_property/about/strategy/23 bDrManujandDrAnton.pdf

Winter, R., Sarros, J. (2002). The academic work environment in australian universities: A motivating place to work. Higher Education Research and Development, 21(3), 241-258.

World Economic Forum (2017). Higher education needs dusting off for the $21 s t$ century. Retrieved form 
https://www.weforum.org/agenda/2018/03/make-higher-educationskills-relevant-for-students/

Zehrer, A. (2007). The justification of journal rankings - A pilot study. Scandinavian Journal of Hospitality and Tourism, 7(2), 139-156. 